\title{
Lapatinib promotes the incidence of hepatotoxicity by increasing chemotherapeutic agent accumulation in hepatocytes
}

\author{
ChunLing Dai ${ }^{1, *}$, ShaoLin Ma ${ }^{1, *}$, Fang Wang ${ }^{1}$, HongYun Zhao ${ }^{1}$, XingPing Wu ${ }^{1}$, \\ ZhenCong Huang ${ }^{1}$, ZheSheng Chen ${ }^{2}$, Kenneth $\mathrm{To}^{3}$ and LiWu Fu ${ }^{1}$ \\ ${ }^{1}$ State Key Laboratory of Oncology in South China, Collaborative Innovation Center for Cancer Medicine, Cancer Center, Sun \\ Yat-sen University, Guangzhou, China \\ 2 Department of Pharmaceutical Sciences, College of Pharmacy and Health Sciences, St. John's University, Queens, NY, USA \\ 3 School of Pharmacy, The Chinese University of Hong Kong, Hong Kong SAR \\ * These authors have contributed equally to this work
}

Correspondence to: Liwu Fu, email: fulw@mail.sysu.edu.cn

Keywords: lapatinib; ABC transporters; hepatotoxicity; pharmacokinetic

Received: February 18,2015 Accepted: April 08, $2015 \quad$ Published: April 23, 2015

This is an open-access article distributed under the terms of the Creative Commons Attribution License, which permits unrestricted use, distribution, and reproduction in any medium, provided the original author and source are credited.

\section{ABSTRACT}

Lapatinib has been used in combination with capecitabine or paclitaxel to treat patients with progressive HER2-overexpressing metastatic breast cancer (MBC). Unfortunately, an increased incidence of hepatotoxicity had been reported in the combinational therapy. The aim of this study was to investigate the potential mechanisms of this combinational therapy. We found that the patients receiving lapatinib and paclitaxel treatment showed a higher incidence of hepatobiliary system disorders than those receiving paclitaxel alone. Lapatinib was shown to increase the accumulation of doxorubicin in ABCB1-overexpressing hepatocellular cancer cells and normal liver tissues without altering the protein level of ABCB1. Pharmacokinetic studies revealed that lapatinib could increase the systematic exposure of paclitaxel and doxorubicin. Moreover, the in vivo experiments showed that the levels of alanine aminotransferase and serious hepatocyte injury in the group of lapatinib plus chemotherapeutic agent were significantly higher than those in the group of single chemotherapeutic agent such as paclitaxel or doxorubicin. Our study thus revealed for the first time that the higher incidence of hepatotoxicity during this combinational treatment was due to the increased drug accumulation in hepatocytes mediated by the inhibition of ABCB1 by lapatinib. Appropriate dose adjustment may be needed to optimize the combination therapy.

\section{INTRODUCTION}

ATP-binding cassette (ABC) transporters play a key role in normal pharmacology, xenobiotic protection, stem cell maintenance and is involved in the multidrug resistance (MDR) phenotype of human cancers [1]. They are efflux transporters that actively extrude a wide variety of chemically unrelated compounds including anthracyclines, vinca alkaloids, epipodophyllotoxins and tanxanes out of cells [2]. P-glycoprotein (ABCB1/MDR1), multidrug resistance-associated protein 1 (ABCC1/ MRP1) and breast cancer resistance protein (ABCG2/ $M X R$ ) are three major $A B C$ transporters associated with
MDR [1]. So far, $\mathrm{ABCB} 1, \mathrm{ABCC} 1$ and $\mathrm{ABCG} 2$ have been found overexpressed in many chemotherapeuticresistant tumors such as colon cancer, liver cancer and kidney cancer [3]. With a crucial protective role, these $\mathrm{ABC}$ transporters are also expressed at high levels in intestinal epithelial cells, proximal renal tubular cells, placental trophoblast cells, the blood brain barrier, and on the biliary surface of hepatocytes $[4,5]$. Under normal physiological condition, the transporters prevent the accumulation of xenobiotics and subsequently reducing toxic effect in various organs [6]. Previously, we showed that lapatinib inhibited the function of $\mathrm{ABC}$ transporters (including $\mathrm{ABCB} 1, \mathrm{ABCC} 1$ and $\mathrm{ABCG} 2$ ) and enhanced 
Table 1: Adverse events in the hepatobiliary system in a cohort of 39 patients.

\begin{tabular}{ccccc}
\hline Group & ALT increased & AST increased & Hyperbilirubinaemia & Total \\
\hline Paclitaxel alone & $1 / 21(4.76 \%)$ & $1 / 21(4.76 \%)$ & $0 / 21(0.00 \%)$ & $2 / 21(4.76 \%)$ \\
Paclitaxel + lapatinib & $4 / 18(22.22 \%)$ & $2 / 18(11.11 \%)$ & $4 / 18(22.22 \%)^{*}$ & $7 / 18(38.89 \%) *$ \\
\hline
\end{tabular}

The data represent the number of subjects (\%) in each group. The $P$ value was calculated by Fisher's exact test. $* P<0.05$ for values versus those in paclitaxel alone.

the anticancer activity of chemotherapeutic agents in $\mathrm{ABC}$ transporter-overexpressing cancer cells [7, 8]. In liver, ABCB1 is expressed at the apical side of bile canaliculus so that the transporter mediates the hepatic elimination of xenobiotics and drugs into the bile [9]. To this end, $\mathrm{ABCB} 1$ has been reported to protect again hepatotoxicity from anticancer drugs such as trabectedin [10]. It follows that the accumulation of conventional ABC substrate chemotherapeutic agents in liver may be increased when the patients were also concomitantly administered with an ABC transporter inhibitor.

Drug-induced hepatotoxicity is a major doselimiting adverse effect hindering the clinical application of many drugs. The U.S. Food and Drug Administration (FDA) had delayed many drugs approval and withdrawn approved drugs from the market because of severe hepatotoxicity, such as bithionol cobalt salts, sulfathiazole and oxyphenisatin [11]. Liver is the major site of drug metabolism and detoxification. More than $80 \%$ of blood flow of liver come from the gastrointestinal tract and the liver has a high capacity for both phase I and phase II biotransformation [12]. Therefore, liver is vulnerable to the toxic effect from chemotherapeutic agents. The most catastrophic consequence is the occurrence of acute liver failure that leads to death or requires liver transplantation. In recent years, the combination chemotherapy is the mainstay treatment option for many cancers. Combination treatment of lapatinib plus capecitabine or letrozole had been used in patients with progressive human epidermal receptor 2 (HER2)-overexpressing metastatic breast cancer [13-15]. A phase III study demonstrated that the combination treatment of lapatinib and capecitabine significantly decreased the risk of disease progression compared to either drug alone [16]. However, an increased hepatobiliary disorders were reported in patients who received the combination treatment of lapatinib with paclitaxel, capecitabine or letrozole [17]. Other tyrosine kinase inhibitors including imatinib, nilotinib, dasatinib, gefitinib, erlotinib, sorafenib, sunitinib, pazopanib have also been reported to cause hepatotoxicity [18]. The underlying mechanisms of tyrosine kinase inhibitorsinduced hepatotoxicity in combination treatment have not been fully elucidated.

In this study, we demonstrated that the increased incidence of hepatotoxicity during the combination treatment of lapatinib with paclitaxel was associated with an increased accumulation of the chemotherapeutic agents. Data from the in vitro and in vivo assays revealed that the increased drug accumulation was due to the inhibition of ABCB1 transport activity by lapatinib. A better understanding of the mechanism of this hepatotoxicity may facilitate the further optimization of the combination regimens composing lapatinib and other chemotherapeutic drugs in clinic.

\section{RESULTS}

\section{A higher incidence of hepatotoxicity was observed in patients receiving combination therapy of lapatinib and paclitaxel than those receiving paclitaxel alone}

From a cohort of 39 patients with HER2overexpressing metastatic breast cancer, we analyzed the adverse events in hepatobiliary system from the start of the medication until 30 days after the last dose. No patients suffered any disease of the hepatobiliary system before receiving the chemotherapy. In the drug combination group (paclitaxel plus lapatinib), 4 patients experienced increased ALT and 2 patients experienced increased AST (Table 1). Most events were grade 1 or 2 according to the National Cancer Institute Common Terminology Criteria for Adverse Events (CTCAE) version 3.0. In addition, 4 patients who received the combination treatment showed hyperbilirubinaemia and one of them had a Grade 3 hyperbilirubinaemia. Furthermore, there was one patient in the group of lapatinib and paclitaxel withdrawn from the treatment because of severe abnormal hepatic function. In contrast, there were only 2 patients in the group of paclitaxel alone showed grade 1 abnormal hepatic function. Therefore, the clinical data showed that the combination therapy (paclitaxel plus lapatinib) group induced significantly more hepatotoxicity than the paclitaxel alone treatment group.

\section{Lapatinib increased doxorubicin accumulation in ABCB1-overexpressing hepatocellular carcinoma cells in vitro}

We hypothesized that the increased hepatotoxicity was associated with elevated drug accumulation induced by lapatinib in the liver. In order to verify our conjecture, we first investigated the effect of lapatinib on increasing 


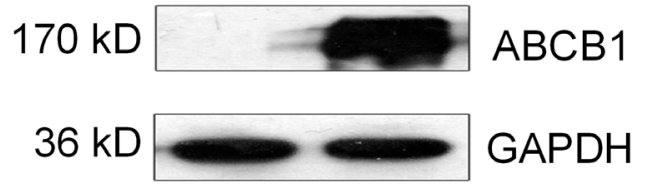

C
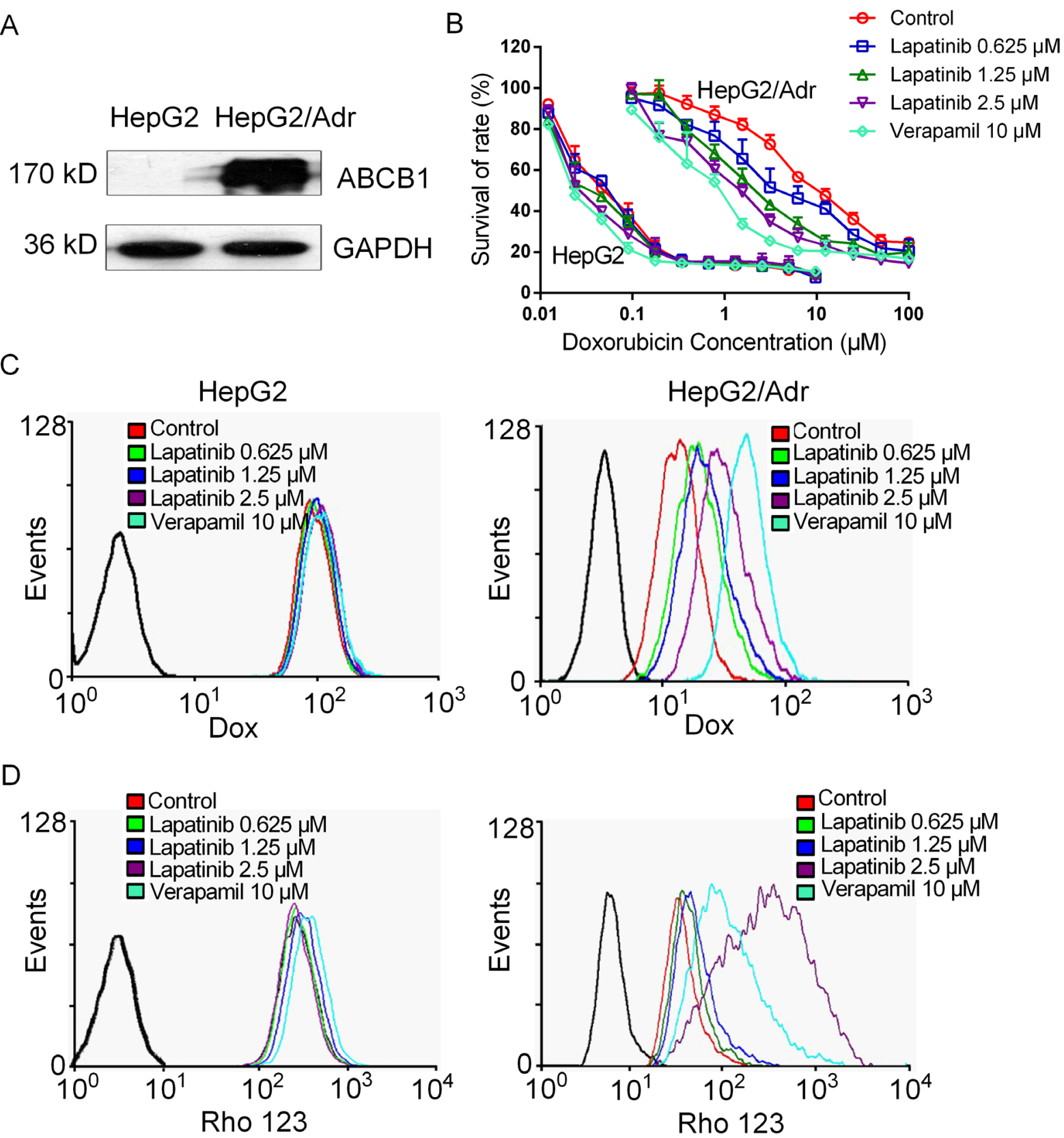

$E$

$\mathrm{F}$
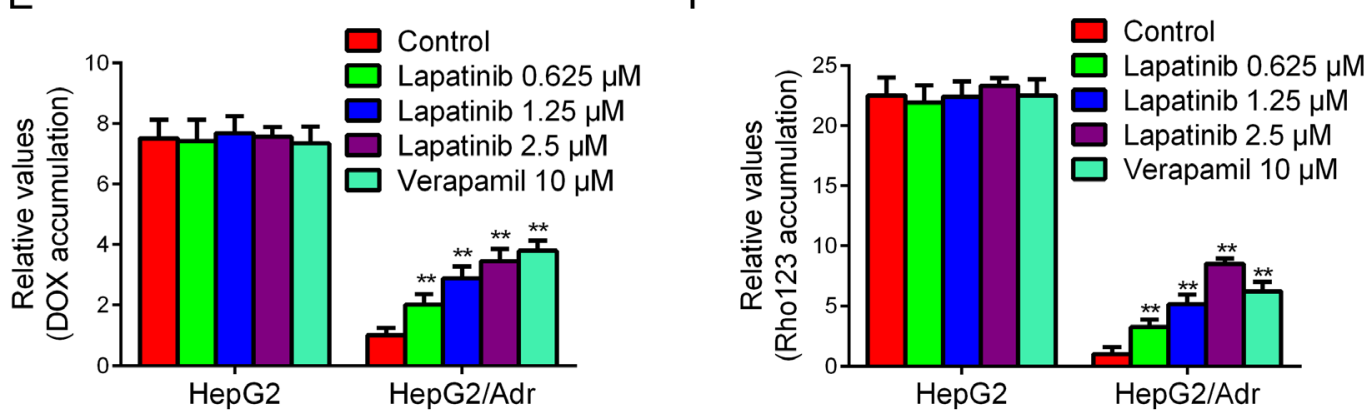

Figure 1: Effect of lapatinib on the accumulations of doxorubicin and rhodamine 123. A. The expression of $A B C B 1$ in HepG2/Adr cells was detected by Western blot. B. Lapatinib enhanced the cytotoxicity effect of doxorubicin on ABCB1-overexpressing HepG2/Adr cells. C. D. E. F. The accumulations of doxorubicin and rhodamine 123 were measured by flow cytometric analysis as described in "Materials and Methods". The results are presented as fold change in fluorescence intensity relative to control MDR cells. ** $P<0.01$ versus control group. The experiment was done at least thrice. 
drug accumulation in a sensitive hepatocellular carcinoma cells HepG2 and its ABCB1-overexpressing resistant HepG2/Adr subline. The upregulation of ABCB1 expression in HepG2/Adr cells was shown as Figure 1A. Lapatinib was found to enhance the cytotoxicity effect of doxorubicin in HepG2/Adr cells in a concentrationdependent manner but not in the parental HepG2 cells (Figure 1B). Compared with the parental HepG2 cells, the intracellular accumulation of doxorubicin or an ABCB1 probe substrate rhodamine 123 in HepG2/Adr cells was decreased, suggesting that ABCB1 overexpression could reduce intracellular substrate accumulation (Figure 1). The fluorescent index of doxorubicin was increased by 1.85 , 2.15-, 3.10-fold in HepG2/Adr cell in the presence of $0.625,1.25$ and $2.5 \mu \mathrm{M}$ of lapatinib, respectively (Figure $1 \mathrm{C}$ and E). Similarly, the fluorescent index of rhodamine 123 was increased by 2.23-, 3.21-, 9.77-fold in HepG2/ Adr cell in the presence of $0.625,1.25$ and $2.5 \mu \mathrm{M}$ of lapatinib, respectively (Figure 1D and $1 F$ ). In contrast, the intracellular accumulations of doxorubicin and rhodamine 123 were not altered in HepG2 cell in the presence of lapatinib.

Since the increased accumulation effect of lapatinib can be achieved either by antagonizing the drug efflux function of $\mathrm{ABCB} 1$ or by decreasing the expression level of $A B C B 1$. We next examined the effect of lapatinib on the expression of $\mathrm{ABCB} 1$ at the mRNA and protein levels by qRT-PCR and Western blot analysis, respectively. As shown in Figure 2, ABCB1 RNA and protein expressions were not significantly altered in HepG2/Adr cells after treatment with lapatinib for 24,48 or $72 \mathrm{~h}$. These results suggested that lapatinib may increase intracellular accumulation of chemotherapeutic agents by inhibiting the function of $\mathrm{ABCB} 1$ without altering the transporter expression level.

\section{Lapatinib enhanced doxorubicin accumulation in normal liver tissues}

To further understand the enhancement of chemotherapeutical agent mediated-hepatotoxicity by lapatinib, we investigated the effect of lapatinib on increasing drug accumulation in normal liver tissues obtained from Swiss mice and cancer patients. We first detected the expression levels of ABCB1 in human liver and mouse liver (6 cases for each group). The PCR results showed that normal human and mice liver both expressed high levels of ABCB1 (Figure 3A). Immunohistochemical staining confirmed that the normal liver specimens had high ABCB1 expression and that ABCB1 was localized on the biliary canalicular surface of hepatocytes and the apical surface of small biliary ductules (Figure 3B and 3C). Importantly, we found that there was much more accumulation of doxorubicin in human and mice liver tissues in the presence of lapatinib than in the absence of lapatinib (Figure 3E). The fluorescent index of doxorubicin was increased by 2.64-fold in human liver tissues when incubated in $2.5 \mu \mathrm{M}$ lapatinib (Figure 3E). Similarly, the fluorescent index of doxorubicin was increased by $2.46-$ fold in Swiss mice liver tissues in the presence of $2.5 \mu \mathrm{M}$ lapatinib (Figure 3E). Taken together, these results suggest that lapatinib could increase accumulation of ABCB1 substrate chemotherapeutical agents not only in ABCB1 overexpressing cancer cells but also in normal liver cells.

\section{Lapatinib altered the pharmacokinetics of paclitaxel and doxorubicin in mice}

Co-administration of lapatinib and an anticancer drug may significantly elevate plasma concentrations of anticancer drug by interfering with its clearance, which will increase the unpredictable side effect of the anticancer drugs $[19,20]$. Since lapatinib has been shown to inhibit $\mathrm{ABCB} 1$, we examined the pharmacokinetic property of paclitaxel and doxorubicin in mice in the presence or absence of lapatinib. Our data indicated that the lapatinib plus paclitaxel combination group showed a significantly longer $\mathrm{T}_{1 / 2} \beta$ and a greater area under concentration-time curve (AUC) than those in the paclitaxel alone group (Figure 4A, Table 2). Moreover, a significantly slower plasma clearance (CL) was observed in the paclitaxel plus lapatinib combination group $(4.87 \mathrm{~mL} / \mathrm{h})$ than in the paclitaxel alone group $(8.35 \mathrm{~mL} / \mathrm{h})$ (Table 2$)$. Similar results were also observed for doxorubicin in the presence or absence of lapatinib (Figure 4B, Table 2). These findings indicated that lapatinib could increase the systematic exposure of ABCB1 substrate chemotherapeutic agents and may thereby increase the chance of adverse effect (e.g. hepatotoxicity) from the chemotherapeutic agents.

\section{Combination of lapatinib and paclitaxel/ doxorubicin resulted in elevated hepatotoxicity in vivo}

The Swiss mice model was used to evaluate the potential hepatotoxic effect of the combination treatment of lapatinib with paclitaxel or doxorubicin. Result of various hepatic function markers were summarized in Table 3. The combination of lapatinib and paclitaxel was found to increase $\operatorname{ALT}(P<0.05)$ and CRE $(P<0.05)$ more significantly than paclitaxel alone. Similarly, the combination of lapatinib and doxorubicin was found to elevate BUN and UA more remarkably than doxorubicin alone. Result from histopathological examination also revealed that the drug combination caused more severe cell necrosis and morphological damages than the chemotherapeutical agent alone (Figure 5). In the combination groups, morphological evidence of hepatocyte damage, including presence of parenchymal acinar transformation zones, vacuolization and hydropic degeneration of hepatocytes, were observed. Furthermore, 
Table 2: The Pharmacokinetic parameters of paclitaxel and doxorubicin were summarized in the presence or absence of lapatinib.

\begin{tabular}{|c|c|c|c|c|c|c|}
\hline Group & $\mathrm{T}_{1 / 2} \beta(\mathrm{h})$ & $\mathrm{Vd}(\mathrm{mL})$ & Clearance $(\mathrm{mL} / \mathrm{h})$ & $\mathrm{AUC} 0 \rightarrow 4(\mathrm{~h} \cdot \mathrm{ng} / \mathrm{mL})$ & AUC0 $\rightarrow \infty(\mathrm{h} \cdot \mathrm{ng} / \mathrm{mL})$ & MRT (h) \\
\hline Paclitaxel alone & $1.24 \pm 0.06$ & $14.96 \pm 1.28$ & $8.35 \pm 1.00$ & $44.24 \pm 4.62$ & $49.26 \pm 5.52$ & $1.42 \pm 0.08$ \\
\hline Paclitaxel + lapatinib & $1.88 \pm 0.21 *$ & $13.22 \pm 1.34$ & $4.87 \pm 0.33 * *$ & $66.48 \pm 4.04 * *$ & $84.50 \pm 5.55$ ** & $1.95 \pm 0.10 * *$ \\
\hline Doxorubicin alone & $5.20 \pm 0.75$ & $3.39 \pm 1.21$ & $3.57 \pm 1.03$ & $2921.15 \pm 841.16$ & $2956.42 \pm 878.46$ & $7.51 \pm 1.08$ \\
\hline Doxorubic in + lapatinib & $15.50 \pm 7.48^{\# \#}$ & $2.28 \pm 0.64$ & $1.95 \pm 0.56^{\# \#}$ & $5338.43 \pm 1519.20$ & $5477.19 \pm 1585.54$ \#\# & $22.36 \pm 10.79^{\# \#}$ \\
\hline
\end{tabular}

The data represent the means and standard deviation of three independent samples and the $P$ value was calculated by student $t$ test. T $1 / 2 \beta=$ Elimination Halflife. $\mathrm{Vd}=$ Apparent volume of distribution. AUC $=$ Area under plasma concentration/time curve. MRT $=$ Mean residence time. $* P<0.05$ and $* * P<0.01$ for values versus those in paclitaxel alone, respectively. ${ }^{\text {\#\# }} P<0.01$ for values versus those in doxorubicin alone.

A
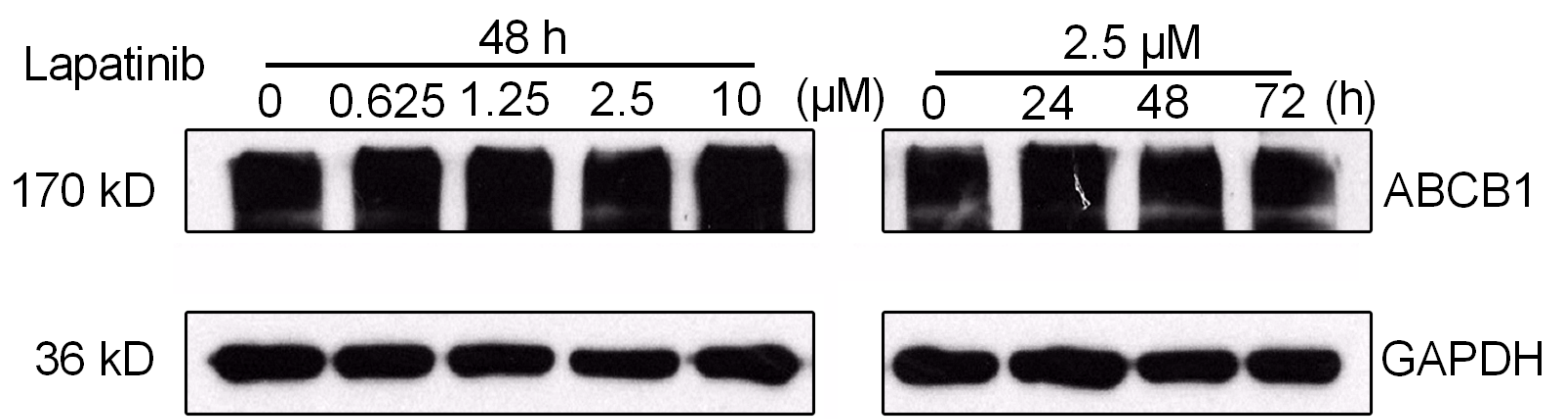

B

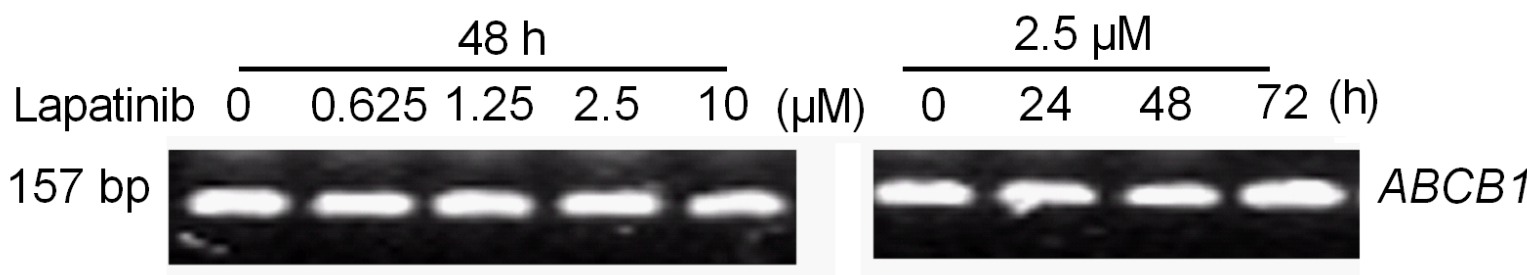

$475 \mathrm{bp}$
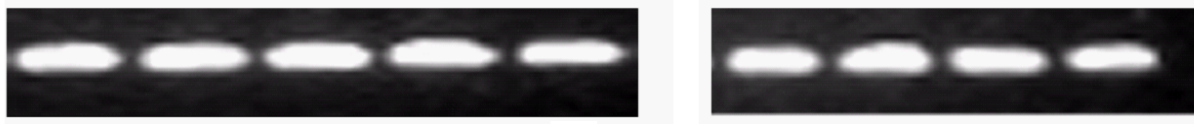

GAPDH

C

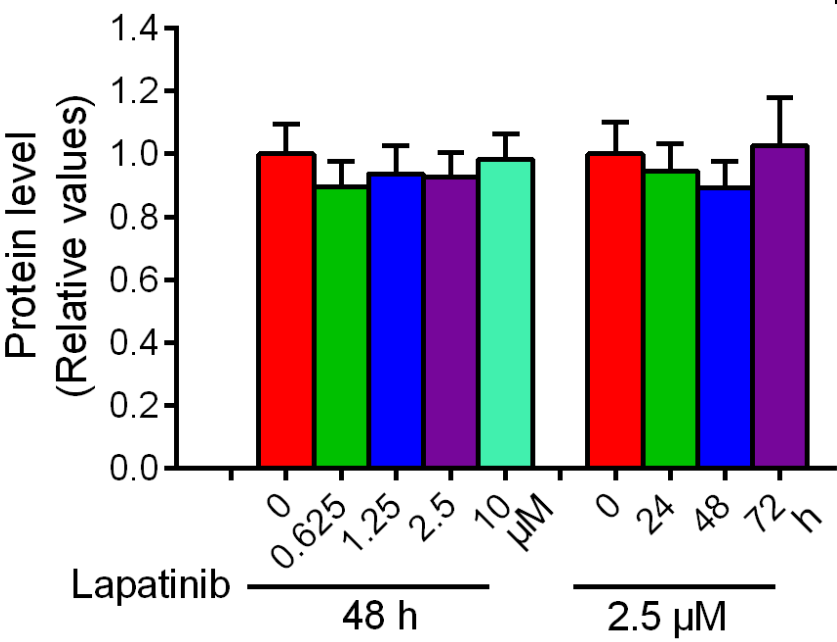

D

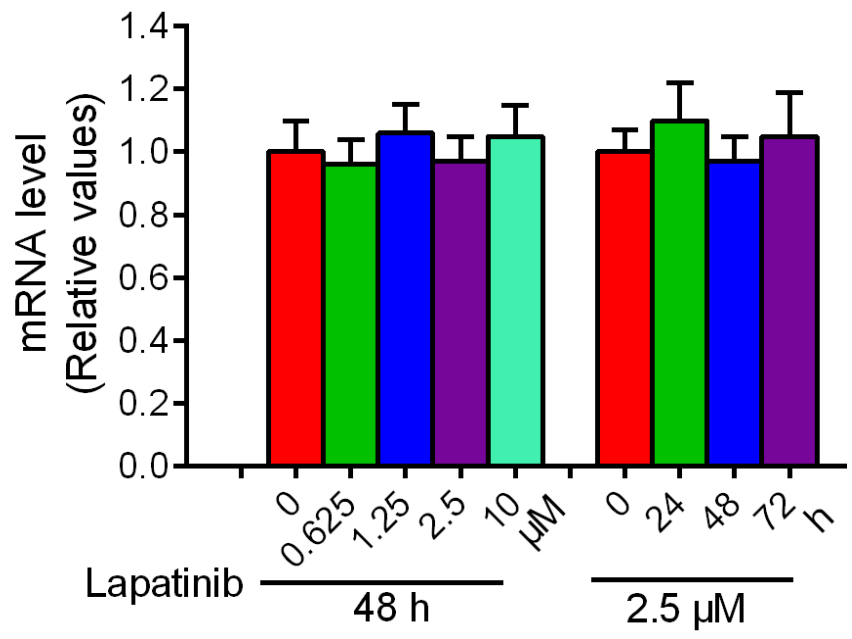

Figure 2: Effect of lapatinib on the expression of ABCB1. The protein level of ABCB1 was measured by Western blot and mRNA level was measured by qRT-PCR. A. B. Lapatinib did not alter the protein levels or mRNA levels in HepG2/Adr cells. C. Grayscale ratios of ABCB1/GAPDH were analyzed with Image J. The grayscale ratios were proportional to the ABCB1 protein levels. D. qRT-PCR was further applied to confirm unchangeable mRNA levels in HepG2/Adr cells. All experiments were repeated at least three times, and a representative set of data is shown in each panel. 
Table 3: Mean values of liver function tests in Swiss mice hepatotoxicity model.

\begin{tabular}{|c|c|c|c|c|c|c|c|c|}
\hline Group & $\begin{array}{l}\text { ALT } \\
(\mathrm{U} / \mathrm{L})\end{array}$ & $\begin{array}{l}\text { AST } \\
(\mathrm{U} / \mathrm{L})\end{array}$ & $\begin{array}{c}\mathrm{UA} \\
(\mathrm{mg} / \mathrm{dL})\end{array}$ & $\begin{array}{l}\text { ALP } \\
(\mathrm{U} / \mathrm{L})\end{array}$ & $\begin{array}{l}\mathrm{LDH} \\
(\mathrm{U} / \mathrm{L})\end{array}$ & $\begin{array}{l}\text { BUN } \\
(\mathrm{U} / \mathrm{L})\end{array}$ & $\begin{array}{c}\mathrm{CRE} \\
(\mu \mathrm{mol} / \mathrm{L})\end{array}$ & $\begin{array}{c}\text { GLOB } \\
(\mathrm{mmol} / \mathrm{L})\end{array}$ \\
\hline Control & $28.22 \pm 6.72$ & $99.27 \pm 11.44$ & $286.4 \pm 64.6$ & $218.51 \pm 51.01$ & $1542.05 \pm 404.84$ & $9.59 \pm 1.14$ & $17.87 \pm 2.16$ & $14.85 \pm 0.25$ \\
\hline Lapatinib & $32.05 \pm 5.57$ & $99.59 \pm 15.55$ & $271.0 \pm 78.7$ & $234.96 \pm 54.33$ & $1732.88 \pm 489.41$ & $10.95 \pm 1.62$ & $18.47 \pm 2.19$ & $14.1 \pm 0.35$ \\
\hline Paclitaxel & $33.90 \pm 6.09$ & $97.94 \pm 23.46$ & $237.3 \pm 72.8$ & $192.35 \pm 32.12$ & $1540.83 \pm 457.35$ & $9.82 \pm 1.38$ & $15.77 \pm 1.78$ & $14.12 \pm 0.44$ \\
\hline $\begin{array}{l}\text { Paclitaxel + lapatinib } \\
\text { Doxorubicin }\end{array}$ & $\begin{array}{c}59.97 \pm 26.72 * \\
22.19 \pm 15.00\end{array}$ & $\begin{array}{c}107.10 \pm 28.67 \\
84.71 \pm 11.08\end{array}$ & $\begin{array}{c}317.8 \pm 75.4 \\
44027 \pm 78.04 *\end{array}$ & $\begin{array}{c}21329 \pm 53.45 \\
1123 \pm 6.91\end{array}$ & $\begin{array}{c}1808.00 \pm 610.33 \\
1606.32 \pm 505.09\end{array}$ & $\begin{array}{c}10.23 \pm 0.97 \\
7.91 \pm 0.82\end{array}$ & $\begin{array}{c}15.39 \pm 1.85^{*} \\
20.17 \pm 7.14\end{array}$ & $\begin{array}{c}17.95 \pm 0.27 \\
18.74 \pm 1.83\end{array}$ \\
\hline Doxorubicin+ lapatinib & $20.43 \pm 8.61$ & $101.44 \pm 10.98$ & $523.42 \pm 50.73 * *$ & $113.85 \pm 18.66$ & $1691.27 \pm 623.47$ & $8.00 \pm 0.90$ & $20.6 \pm 5.50$ & $20.80 \pm 1.97 *$ \\
\hline
\end{tabular}

The $P$ value was calculated by student $t$ test. The values represent mean \pm standard deviation in the triplicate determination. $* P<0.05$ and $* * P<0.01$ for values versus those in control.

A
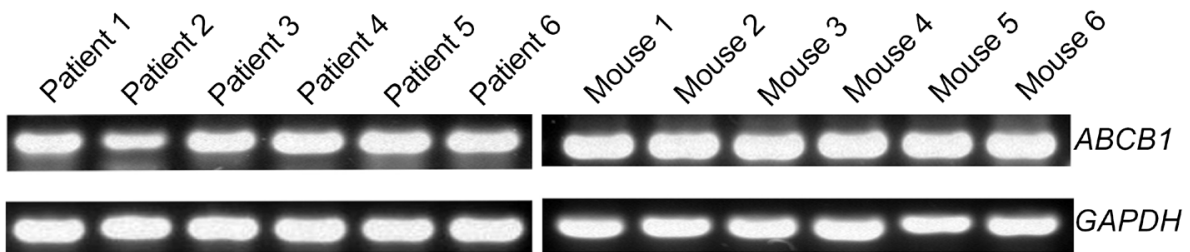

B
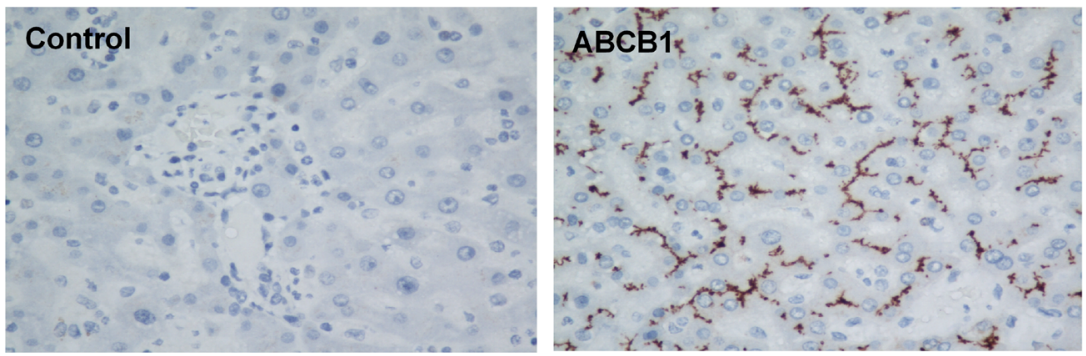

C
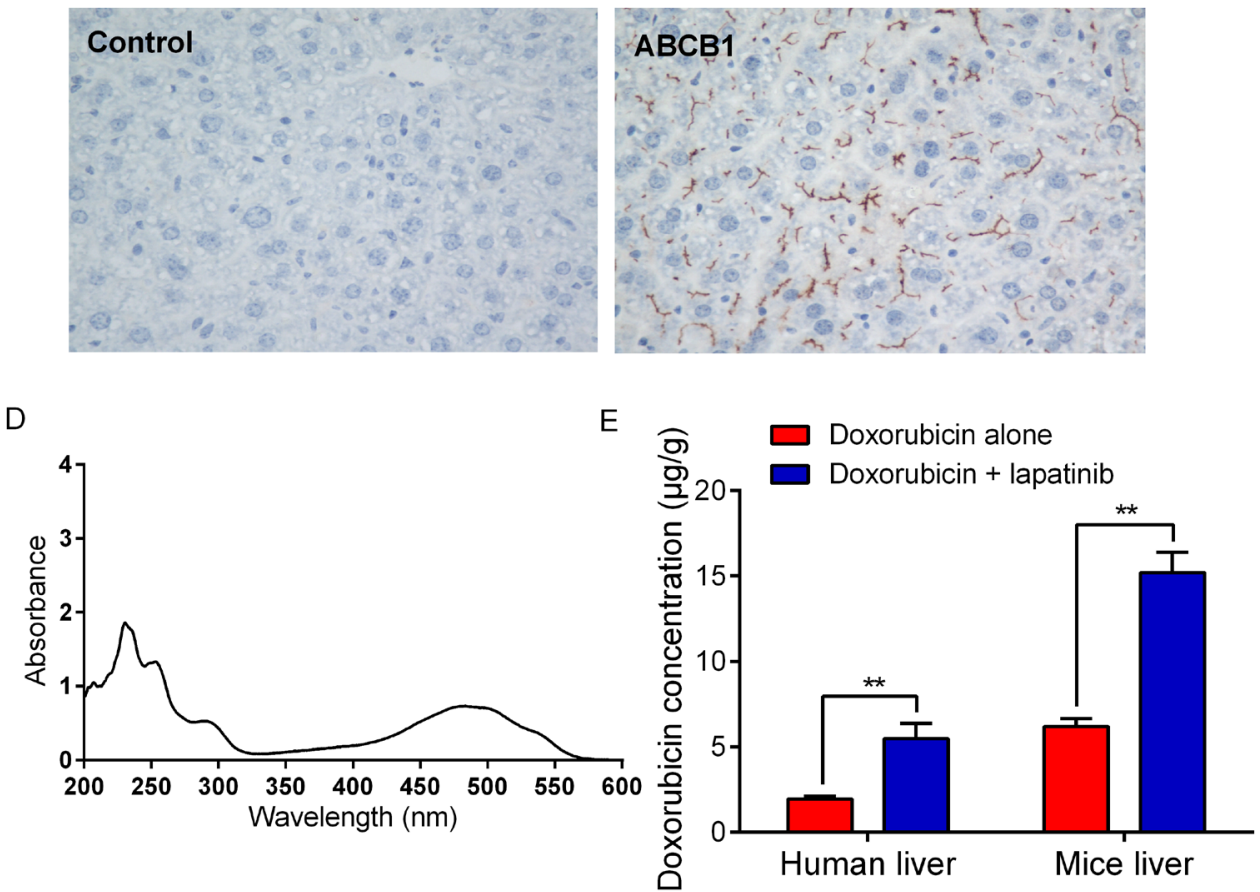

Figure 3: Expression levels of $\mathrm{ABCB} 1$ and doxorubicin accumulation in normal liver tissues. The mRNA level was determined by qRT-PCR as described in "Materials and Methods": A. the mRNA level of ABCB1 in normal liver tissues; B. Sections of human liver reacted with ABCB1 antibody, demonstrating localization in bile canaliculi and hepatocytes. C. Sections of mice liver reacted with $\mathrm{ABCB} 1$ antibody, demonstrating localization in bile canaliculi and hepatocytes; The magnification is $400 \times$. D. The absorption spectra for doxorubicin $(0.5 \mathrm{mg} / \mathrm{ml})$ is detected by UV spectrophotometric method. E. lapatinib increased the doxorubicin accumulation in normal liver tissues. All experiments were done at least thrice. 
extensive inflammation of the hepatocytes was also noted, as indicated by the presence of mononuclear cells besides neutrophil and eosinophil leucocytes in the portal areas. On the other hand, much milder morphological changes of the hepatocytes were observed in paclitaxel/doxorubicin alone group. Given the biochemical and histological results, we concluded that the combination therapy could produce a severe toxicity to liver.

\section{DISCUSSION}

The combination of lapatinib and paclitaxel is an effective first-line therapy in patients with HER2-positive metastatic breast cancer $[21,22]$. However, it has been reported that combination of lapatinib and paclitaxel or capectiabine was associated with a higher incidence of hepatotoxicity. Abnormal liver function tests were observed in patients receiving the combination regimens in a number of clinical trials, including one conducted in China with a high incidence of hyperbilirubinaemia (34.6\%) [23]. Hepatic dysfunction is a leading cause of acute liver failure and it is the major reason for termination of medicines during their clinical development or early withdrawal following approval $[24,25]$. The mechanisms causing the increased hepatotoxicity in combination therapy of lapatinib and paclitaxel are not well defined. In the present study, we first reported a potential mechanism of the increased hepatotoxicity via the inhibition of $A B C$ transporters by lapatinib. Our study indicated that patients are more vulnerable to drug-induced hepatotoxicity upon treatment with combination of lapatinib and substrate drugs of $\mathrm{ABC}$ transporters such as paclitaxel and doxorubicin.

To illustrate the potential mechanism, we found
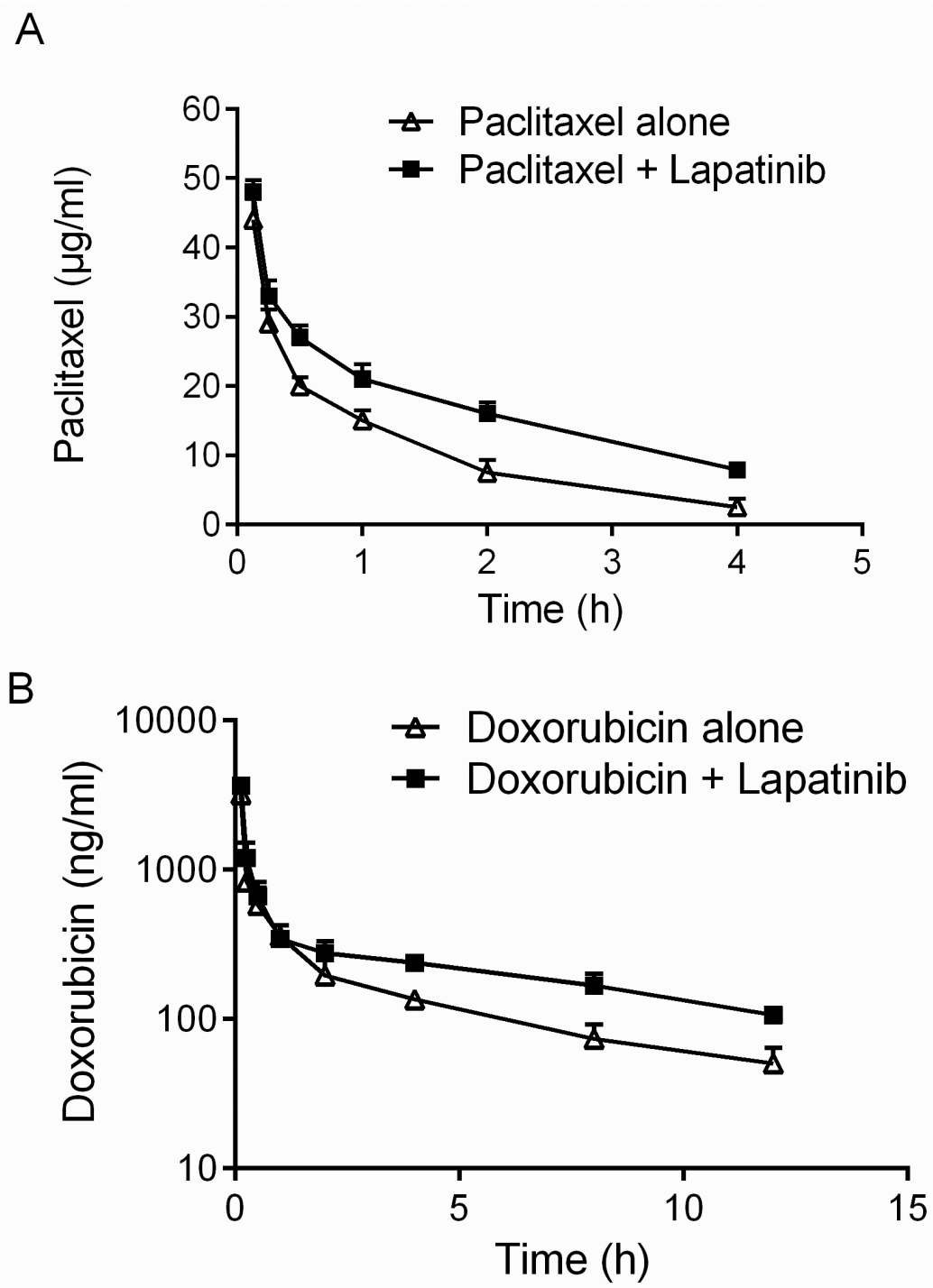

Figure 4: Effect of lapatinib on pharmacokinetics of paclitaxel and doxorubicin. A. B. Effect of lapatinib on the profile of paclitaxel and doxorubicin pharmacokinetics in mice. NIH mice were p.o. administered with or without lapatinib $(100 \mathrm{mg} / \mathrm{kg}) 1 \mathrm{~h}$ before i.v. administration of paclitaxel $(18 \mathrm{mg} / \mathrm{kg})$ or doxorubicin $(10 \mathrm{mg} / \mathrm{kg})$. HPLC analysis was performed as described in the "Material and Methods". The values represent mean \pm standard deviation in the triplicate determination. 
that lapatinib remarkably increased the accumulation of doxorubicin and rhodamine 123 in ABCB1-overexpressing hepatocellular carcinoma cells and normal liver tissues in concentration-dependent manners. However, lapatinib did not significantly increase the drug accumulation in the parental sensitive cells to the anticancer agents. Since lapatinib did not alter the mRNA and protein expressions of $A B C B 1$, the elevated drug accumulation of ABCB1 substrate chemotherapeutic drugs must be mediated by the inhibitory effect of lapatinib on $\mathrm{ABCB} 1$ transport activity $[7,8]$. The in vitro drug accumulation assay and the pharmacokinetic study further confirmed that the increased hepatotoxicity by the drug combination was mediated by the increased drug accumulation induced by lapatinib. As a result, taking our data into account, the hepatoprotective effects could well be the result of inhibiting ABCB1 function. As our study showed, lapatinib would likely exacerbate the hepatotoxic effects of paclitaxel or doxorubicin rather than reduce them. Our findings have important implications for the clinical use of lapatinib in combination with $\mathrm{ABCB} 1$ substrate anticancer drugs. Doxorubicin and paclitaxel, which are commonly used in treating breast cancer, are all ABCB1 substrates. Possible drug-drug interactions with lapatinib may occur and cause severe hepatotoxicity. Therefore, evaluating genetic polymorphism of $\mathrm{ABCB} 1$ in patient before the commencement of treatment might be considered, especially when TKIs are included in the combination regimen, because the likelihood of hepatotoxicity may be predicted.

Combination chemotherapy of molecular targeted agents with other cytotoxic anticancer drugs has attracted a lot of attention recently. Early studies showed that gefitinib enhanced the anticancer activity of irinotecan by inhibiting $\mathrm{ABCB} 1$ and $\mathrm{ABCG} 2$ function, thereby increasing oral bioavailability and reducing clearance of topotecan in mice [26, 27]. Co-administration of lapatinib and irinotecan was also found to increase the area under the plasma concentration-time curve of SN38 , the active metabolite of irinotecan and ABCB1 substrate [28]. In a phase III trial of HER2-positive metastatic breast cancer patients whose cancers had not responded to trastuzumab or other therapies, superior therapeutic response were obtained by combination of lapatinib and capecitabine, compared with capecitabine alone [29]. Moreover, lapatinib given in combination with tamoxifen (substrate of ABCB1) was also found to effectively inhibit cell proliferation and restore tamoxifen sensitivity in ER-positive and tamoxifen-resistant breast cancer [30]. While lapatinib was also shown to
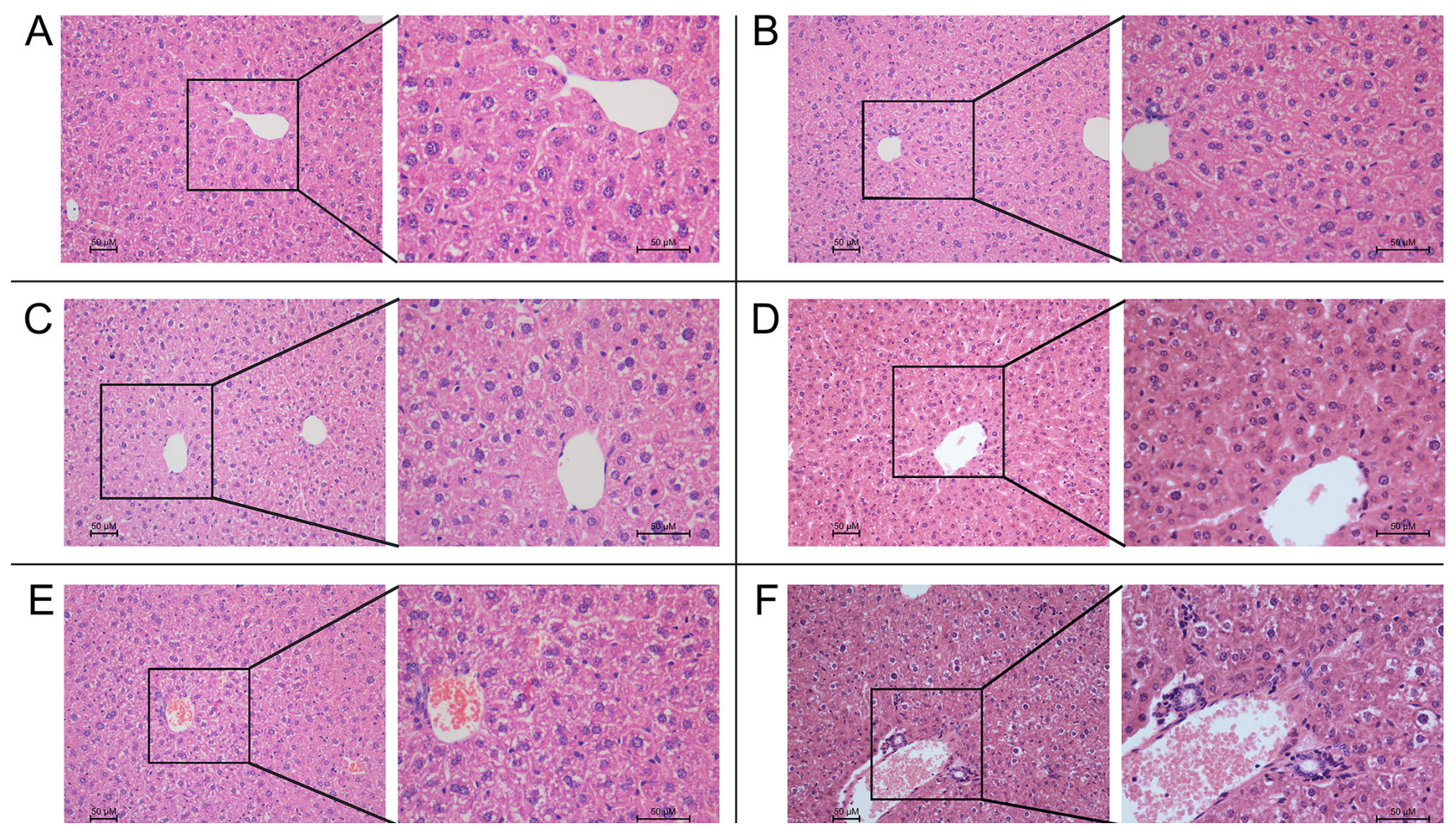

Figure 5: The histological results in in vivo experiments. HE staining of liver tissues (Main-figure: magnification $\times 200$; Subfigure: magnification $\times 400$ ) A. Normal liver parenchyma; B. (group of lapatinib alone) shows a similar histology to the normal group; C. (group of paclitaxel alone) shows mild liver damage: hepatocytes with hydropic changes and monocytes infiltration around the central vein; D. (group of doxorubicin alone) shows mild central venous hyperemia, Hepatic cord disorder and vacuolar degeneration; E. (group of lapatinib and paclitaxel) and $\mathbf{F}$. (group of lapatinib and doxorubicin) show severe liver damage: severe inflammation with neutrophil and eosinophil in portal area, focal necrosis in lobular area, apoptotic body in periportal area. The values represent mean \pm standard deviation in the triplicate determination. 
provide clinical benefit when used in combination with other anticancer drugs in patients with brain metastasis breast cancer by promoting drug penetration through the blood brain barrier [31]. Penetration of taxanes and vinorelbine across the placenta was known to be regulated by $\mathrm{ABCB} 1$. By inhibiting $\mathrm{ABCB} 1$, co-administration lapatinib and paclitaxel has been shown to obscure the normal development of the fetal kidney and the regimen should be avoided during pregnancy [32]. We have previously demonstrated that lapatinib could reverse the ABC transporters-mediated MDR by inhibiting the efflux function of the transporters [7]. Therefore, the adverse effect from the lapatinib-containing combination regimens could be due to the inhibition of ABC transporters at important biological barriers. In fact, the pharmacokinetic drug-drug interactions related to the combination use of MDR modulators with other ABC transporter substrate drugs have been reported [33, 34], which necessitated dose reduction of the anticancer drugs in order to avoid adverse effects. Therefore, in this study, we deliberately set out to investigate the pharmacokinetics of paclitaxel and doxorubicin in the presence or absence of lapatinib. In human pharmacokinetic studies, the highest peak plasma lapatinib concentration was roughly $3 \mu \mathrm{M}$ and the halflife was approximately $17 \mathrm{~h}$ with achievement of steadystate concentration after six to seven days of once-daily

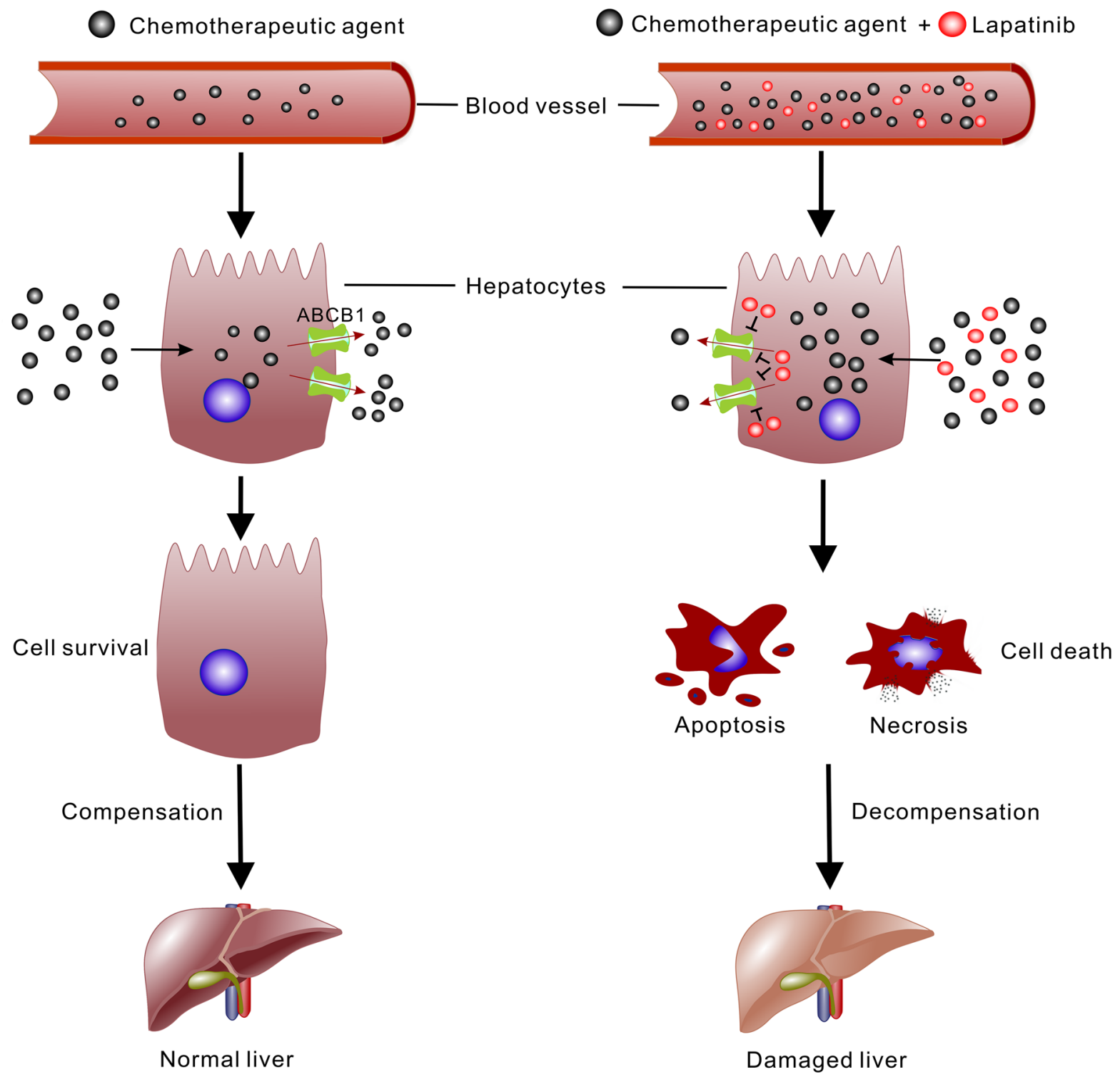

Figure 6: Schematic illustration of the mechanism of lapatinib promoting the cytotoxic effect of chemotherapeutic agent in liver. Lapatinib can interfere with the distribution of agent and increase the plasma concentration. In hepatocytes, the chemotherapeutic agent is excreted out of the cells by $\mathrm{ABC}$ transporters (mainly ABCB1). Lapatinib inhibits the function of $\mathrm{ABCB} 1$ and elevates the concentration of chemotherapeutic agent in hepatocytes. Consequently, the hepatocytes develop into apoptosis or necrosis and the hepatic function is disordered. 
dosing $[35,36]$. Therefore, the concentrations of lapatinib investigated in our in vitro experiments are clinically relevant. Our result proved that lapatinib significantly increased the exposure level of paclitaxel and doxorubicin in mice (Table 3). These suggest pharmacokinetics of conventional chemotherapeutic agent may be altered in the presence of lapatinib.

In the in vivo animal study, the hepatotoxicity marker (ALT) was found to be much more remarkable upregulated after treatment with the drug combination (lapatinib and paclitaxel) than the individual drug alone. The observed increased serum ALT is almost always a consequence of release by dead or dying hepatocytes, and is a sensitive semi-quantitative measure of liver injury. Serum ALT elevations can identify hepatocyte injury or necrosis, which can be transient, as the liver adapts to repair toxic injury. This compensation action in the liver could explain why the ALT level in group of lapatinib and doxorubicin was not raised. From the above we can conclude that the treatment of lapatinib plus paclitaxel or doxorubicin could cause a severe liver injury than the single-agent treatment. Hepatotoxicity induced by lapatinib-containing combination was further confirmed by histopathological examination of liver tissue specimens. The histopathological evaluations demonstrated hydropic degeneration, vacuolated hepatocytes, portal inflammation and additionally apoptotic cells and lobular focal necrosis with extended exposure in the combination group of lapatinib and paclitaxel or doxorubicin. In addition, we observed a serious sinusoidal injury and hyperemia in the combination treatment group. These pathological changes are consistent with the cytotoxic effects induced by paclitaxel and doxorubicin. The morphology of the liver injury induced by doxorubicin is related to the hydropic degeneration, hemorrhage, heavy centrilobular spotting and extensive depletion in glycogen while the morphological changes in liver induced by paclitaxel are inflammatory cell infiltrates and foci, sinusoidal expansion, vesicular degeneration, and necrotic cells [37, 38]. However, all of these features were absent from livers of mice receiving monotherapy (paclitaxel or doxorubicin) treatment at the dose tested. These results indicated that lapatinib could exacerbate the liver injury induced by paclitaxel and doxorubicin. It has been reported that doxorubicin and paclitaxel could damage rat liver by inducing oxidative stress [39]. Further studies are needed to evaluate whether lapatinib could enhance the effects of paclitaxel and doxorubicin through promoting oxidative stress.

In conclusion, the present study demonstrated for the first time the hepatotoxicity caused by the coadministration of lapatinib and paclitaxel/doxorubicin by both biochemical and histopathological evaluation. We showed that lapatinib can increase the accumulation of chemotherapeutic agents especially $\mathrm{ABCB} 1$ substrates in liver to give rise to the higher incidence of hepatotoxicity
(Figure 6). Given that $\mathrm{ABC}$ transporters are also highly expressed in many normal organs such as liver, colon, kidney and brain, dose adjustment of the concomitantly administered chemotherapeutic drugs is needed to avoid adverse events including hepatotoxicity in combination regiment involving $\mathrm{ABC}$ transporter inhibitor.

\section{MATERIALS AND METHODS}

\section{Chemicals and reagents}

Doxorubicin (Dox), paclitaxel, verapamil, 3-(4,5-dimethylthiazol-yl)-2,5- diphenyllapatinibrazolium bromide (MTT) and rhodamine 123 (Rho 123) were purchased from Sigma Chemical Co. (St. Louis, MO, USA). Lapatinib was purchased from LC laboratories (Woburn, MA, USA). Dulbecco's modified Eagle's medium (DMEM) were products of Gibco BRL (Grand Island, NY, USA). Monoclonal antibodies against ABCB1 were purchased from Santa Cruz Biotechnology Inc (Santa Cruz, CA, USA). Other routine laboratory reagents were of analytical grade obtained from various commercial sources (Guangzhou, China).

\section{Cell lines and cell culture}

The human hepatocellular carcinoma cell line HepG2 was obtained from American Type Culture Collection (ATCC). The Dox-selected derivative ABCB1overexpressing HepG2/Adr subline was established as previous study [40]. All cells were grown in DMEM supplemented with $10 \%$ fetal bovine serum, 100 units/ $\mathrm{mL}$ streptomycin sulfate and 100 units $/ \mathrm{mL}$ penicillin $\mathrm{G}$ sulfate, and maintained at $37^{\circ} \mathrm{C}$ in the presence of $5 \%$ $\mathrm{CO}_{2}$. HepG2/Adr cells were cultured with $1.2 \mu \mathrm{M}$ Dox to maintain its $\mathrm{ABCB} 1$-overexpressing properties [40]. All cells were grown in drug-free culture medium for more than 2 weeks before assay.

\section{Patients}

The medical history of a total of 39 patients with HER2-overexpressing MBC (March 2006 - October 2008) were retrieved from the database archive of the Sun Yat-sen University (Guangzhou, China) for analysis. All patients were diagnosed with invasive breast cancer by histological examination. The HER 2 overexpression was confirmed by fluorescence in situ hybridization. 18 patients received the combination treatment (lapatinib $1500 \mathrm{mg}$ daily plus paclitaxel $80 \mathrm{mg} / \mathrm{m}^{2}$ every 3 days) and the control group received only paclitaxel $\left(80 \mathrm{mg} / \mathrm{m}^{2}\right.$ every 3 days). The median age is 50.5 years (age range from 21 to 65 years). 


\section{Western blot analysis}

The HepG2 and HepG2/Adr cells were exposed to different concentrations of lapatinib $(0.625,1.25,2.5$ and $10 \mu \mathrm{M})$ for different periods $(0,24,48$ and $72 \mathrm{~h})$ to test whether lapatinib affected the expression of ABCB1. Western blot analysis was conducted as previously described [7]. After being incubated in blocking solution containing $5 \%$ non-fat milk in TBST buffer $(10 \mathrm{mM}$ TrisHCL (pH 8.0), $150 \mathrm{mM} \mathrm{NaCl}$, and $0.1 \%$ Tween 20) for 2 $\mathrm{h}$ at room temperature, membranes were incubated with primary antibody ABCB1 (1:1000 dilution, Santa Cruz Biotechnology) and GAPDH (1:5000 dilution, Kangcheng Biotechnology). The membranes were then incubated for $2 \mathrm{~h}$ with HRP-conjugated secondary antibody at 1:5000 dilution. Immunoreactive bands were visualized by the enhanced Phototope TM-HRP Detection Kit (Cell Signaling, USA) and exposed to Kodak medical X-ray processor (Carestream Health, USA). Protein expression was quantified by Scion Image software (Scion Co, USA).

\section{Cytotoxicity}

We collected the cells and seeded them at a density of $3.0 \times 10^{3}$ cells per well in 96-well plates. After 24 $\mathrm{h}$, different concentrations of doxorubicin were added into the wells $1 \mathrm{~h}$ after lapatinib was added. After $68 \mathrm{~h}$, MTT $(5 \mathrm{mg} / \mathrm{mL}, 20 \mu \mathrm{L})$ was added into each well and cultured for another $4 \mathrm{~h}$. Then the medium was discarded and each well was added with $120 \mu \mathrm{L}$ DMSO. Finally, optical density was measured at $540 \mathrm{~nm}$ with background subtraction at $670 \mathrm{~nm}$ by Model 550 Microplate Reader (Bio-Rad, Hercules, CA, USA).

\section{Doxorubicin and rhodamine 123 accumulation}

The accumulation of doxorubicin or rhodamine 123 in HepG2 and HepG2/Adr cells was measured as previously described [41]. Verapamil, a known ABCB1 inhibitor, was used as a positive control [42].

\section{Ex vivo evaluation of doxorubicin accumulation in patient liver tissues}

The fresh normal liver tissue adjacent to the hepatocellular carcinoma retrieved from Sun Yatsen university cancer center was used for the drug accumulation assay ex vivo. Informed consent was obtained from the patients before tissue collection. The work was approved by the ethics review committee at Sun Yat-sen University (Guangzhou, China). Liver tissues of 50-100 mg were cut into small pieces $\left(1 \mathrm{~mm}^{3}\right)$ and cultured in DMEM containing $15 \%$ fetal bovine serum at $37^{\circ} \mathrm{C}$. The tissues were incubated with the desired concentration of lapatinib at $37^{\circ} \mathrm{C}$ for $1 \mathrm{~h}$ in the medium, and then 10 $\mu \mathrm{M}$ doxorubicin was added to the medium and further incubated for $6 \mathrm{~h}$. Subsequently, the tissues were then collected, centrifuged and washed twice with cold PBS containing $10 \mu \mathrm{M}$ verapamil. Then, liver tissues were resuspended in $1 \mathrm{ml} / 100 \mathrm{mg}$ tissues lysis solution which contained $0.3 \mathrm{~mol} / 1 \mathrm{HCl}$ and $60 \%$ ethanol (1:1) and was homogenized at $4^{\circ} \mathrm{C}$ and then centrifuged at $12000 \times \mathrm{g}$ [43]. The supernatant was removed and its fluorescence signal was measured by a spectrofluorometer at $\lambda_{e x} 470$ $\mathrm{nm}$ and $\lambda_{e m} 590 \mathrm{~nm}$. Simultaneously, the standard curve of doxorubicin was made with the same condition. The doxorubicin accumulation in liver tissues $(\mu \mathrm{g} / \mathrm{g})$ was calculated according to the fluorescence value using a standard curve.

\section{Immunohistochemistry}

Immunohistochemical staining for $\mathrm{ABCB} 1$ expression was performed using a standard twostep method [44]. The tissues were fixed with $4 \%$ paraformaldehyde in $0.1 \mathrm{M}$ phosphate buffer for $24 \mathrm{~h}$. After fixation, the tissues were embedded in paraffin wax. The paraffin tissues were sliced into $14 \mu \mathrm{M}$ sections and mounted onto glass slides. After dewaxing, antigen retrieval was facilitated in Tris-EDTA buffer $(\mathrm{pH}$ 9.0) and the tissue sections were then incubated with primary antibodies against ABCB1 (1:100 dilution, Santa Cruz Biotechnology) for overnight at $4^{\circ} \mathrm{C}$. Then the slides were washed three times with PBS and subsequently incubated with second antibodies and stained with 3,3-diaminobenzidine tetrahydrochloride (DAB). Finally, the slides were counter stained with Mayer's hematoxylin. Slides immunoreacted with only second antibodies provided the background staining for comparison. All slides were examined with a Nikon Eclipse 80i microscope and images were captured with NIS-Elements F 3.2 imaging analysis system.

\section{Swiss mice hepatotoxicity model}

Swiss mice, 5 - 6 weeks of age and weighing about $20 \mathrm{~g}$, were obtained from the Center of Experimental Animals, Sun Yat-sen University (Guangzhou, China) and were randomized into six treatment groups: (1) saline (on day 1 and 2 of every week for 2 weeks); (2) lapatinib alone (on day 1 and 2 of every week for 2 weeks, p.o., $100 \mathrm{mg} / \mathrm{kg}$ ); (3) paclitaxel alone (on day 2 of every week for 2 weeks, i.v., $18 \mathrm{mg} / \mathrm{kg}$ ); (4) paclitaxel (i.v., $18 \mathrm{mg} /$ $\mathrm{kg}$ ) one hour after lapatinib on day 2 of every week, (5) doxorubicin alone (every three days for 2 weeks, i.v., $10 \mathrm{mg} / \mathrm{kg}$ ); (6) doxorubicin (i.v., $10 \mathrm{mg} / \mathrm{kg}$ ) one hour after lapatinib (p.o., $100 \mathrm{mg} / \mathrm{kg}$ ) every three days. The experimental animals had free access to sterilized food and water. Liver function was evaluated by measuring 
the levels of aspartate aminotransferase (AST), alanine aminotransferase (ALT), total bilirubin, albumin and alkaline phosphatase (ALP), lactate dehydrogenase (LDH), gamma glutamyl transferase (GGT). After 2 weeks, all mice were euthanized by cervical dislocation and unprocessed blood and tissues samples were quickly obtained from the mice. Liver tissues specimens were fixed in $10 \%$ formaldehyde and embedded in paraffin blocks. Sectioned slices were stained with haematoxylin and eosin (H\&E), and each section was analyzed at 200 and $400 \cdot$ magnification by Nikon Eclipse 80 i microscope. All of the pathological slides were independently and blindly evaluated by two pathologists (Dr Shixun Lu and Dr Rongzhen Luo) from the department of pathology of Sun Yat-sen University Cancer Center. All animal care and experimental procedures were approved by the Ethics Committee for Animal Experimentation and were carried out in accordance with the guidelines on animal care and experiments of laboratory animals (Center of Experimental Animals, Sun Yat-sen University, China).

\section{Pharmacokinetic study in NIH mice}

Male and female NIH mice weighing 20-23 g were obtained from the Center of Experimental Animals, Sun Yat-sen University (Guangzhou, China) for the pharmacokinetic study. The mice were randomly divided into four groups (paclitaxel alone, doxorubicin alone and their combination with lapatinib), each of which consisted of 6 mice (three males and three females). For plasma paclitaxel levels, mice were treated with either $100 \mathrm{mg} /$ $\mathrm{kg}$ of lapatinib (p.o.) or vehicle on days 1 and 2 and on day 2 all mice were injected with $18 \mathrm{mg} / \mathrm{kg}$ of paclitaxel $(10 \mathrm{~mL} / \mathrm{kg})$ via the caudal vein one hour after lapatinib or vehicle. For plasma doxorubicin levels, mice were treated with either $100 \mathrm{mg} / \mathrm{kg}$ of lapatinib (p.o.) or vehicle on days 1 and 2 and on day 2 all mice were injected with 10 $\mathrm{mg} / \mathrm{kg}$ of doxorubicin $(10 \mathrm{~mL} / \mathrm{kg})$ via the caudal vein one hour after lapatinib or vehicle. Blood was collected from the retro-orbital plexus at designated time points and they were kept in cold heparin coated glass tubes. The blood from 1 male and 1 female was pooled and plasma was isolated and stored at $-80^{\circ} \mathrm{C}$ until analysis. The plasma levels of paclitaxel and doxorubicin were analyzed by HPLC as previously described (20). Pharmacokinetic parameters was determined from the concentration-time data by non compartment model using the 3P97 software (Practical Pharmacokinetics Software, Beijing, China). All experiments were approved by Ethics Committee for Animal Experiments and carried out in accordance with the guidelines on Animal Care and Experiments of Laboratory Animals of Center of Experimental Animals, Sun Yat-sen University.

\section{Reverse transcription-PCR}

Total cellular RNA was isolated by Trizol Reagent (Gibco BRL, USA) RNA extraction kit following manufacture instruction. cDNA were prepared from the sensitive HepG2 and the resistant HepG2/Adr cells. Reverse transcription was done with reverse transcriptase (Promega Corp., Madison, WI). Oligonucleotides primers for $A B C B 1$ and $G A P D H$ were synthesized commercially (Invitrogen Co., China). They included $A B C B 1$ (homo sapiens), sense primer, 5'-CCCATCATTGCAATAGCAGG-3', antisense primer, 5'-GTTCAAACTTCTGCTCCTGA-3'; Abcbl (mus), sense primer, 5'-CCCATGGCTGCATCAGTGTT-3', antisense primer, 5'-GCTGAGTGCCTTTGTCTCCT-3'; GAPDH, sense primer, 5' GAAGGTGAAGGTCGGAGTC-3', antisense primer, 5'-GAAGATGGTGATGGGATTTC-3'. Regular PCR was performed at $94^{\circ} \mathrm{C}$ for $2 \mathrm{~min}$ for initial denaturation, and then at $94^{\circ} \mathrm{C}$ for 30 seconds, $56^{\circ} \mathrm{C}$ for 30 seconds, and $72^{\circ} \mathrm{C}$ for 1 min using the GeneAmp PCR system 9700 (PE Applied Biosystem, Foster City, CA). After 35 cycles of amplification, additional extensions were done at $72^{\circ} \mathrm{C}$ for $10 \mathrm{~min}$. Products were resolved and examined by $1 \%$ agarose gel electrophoresis [45]. For qRT-PCR analysis, the reaction was carried out at $50^{\circ} \mathrm{C}$ for $2 \mathrm{~min}, 95^{\circ} \mathrm{C}$ for 5 min and 40 cycles at $95^{\circ} \mathrm{C}$ for $15 \mathrm{~s}, 60^{\circ} \mathrm{C}$ for $30 \mathrm{~s}$. Relative quantification of $A B C B 1$ was performed using the $2^{-\triangle \Delta C t}$ method [46]. All experiments were repeated three times.

\section{Statistical analysis}

The Fisher's exact test was used to evaluate the statistical significance in clinical data. In all other experiments, statistical significance was determined at $P$ $<0.01(* *)$ or $P<0.05(*)$ by the Student's $t$-test. The data was expressed as means \pm standard deviation.

\section{ACKNOWLEDGMENTS}

This work was supported by the Grants from Chinese National Natural Sciences Foundations (No. 81061160507 and 81072669) and Chinese Ministry of Education Post doctor Foundation (No. 20100470959) and Excellent Dissertation Foundation of Guangdong Province (No.8400-3226201).

\section{CONFLICTS OF INTEREST}

No potential conflicts of interest were disclosed.

\section{REFERENCE}

1. Sun YL, Patel A, Kumar P and Chen ZS. Role of ABC 
transporters in cancer chemotherapy. Chinese journal of cancer. 2012; 31:51-57.

2. Ambudkar SV, Kimchi-Sarfaty C, Sauna ZE and Gottesman MM. P-glycoprotein: from genomics to mechanism. Oncogene. 2003; 22:7468-7485.

3. Gottesman MM, Hrycyna CA, Schoenlein PV, Germann UA and Pastan I. Genetic analysis of the multidrug transporter. Annual review of genetics. 1995; 29:607-649.

4. Iusuf D, Teunissen SF, Wagenaar E, Rosing H, Beijnen JH and Schinkel AH. P-glycoprotein (ABCB1) transports the primary active tamoxifen metabolites endoxifen and 4-hydroxytamoxifen and restricts their brain penetration. The Journal of pharmacology and experimental therapeutics. 2011; 337:710-717.

5. Thiebaut F, Tsuruo T, Hamada H, Gottesman MM, Pastan I and Willingham MC. Cellular localization of the multidrugresistance gene product P-glycoprotein in normal human tissues. Proceedings of the National Academy of Sciences of the United States of America. 1987; 84:7735-7738.

6. Maliepaard M, Scheffer GL, Faneyte IF, van Gastelen MA, Pijnenborg AC, Schinkel AH, van De Vijver MJ, Scheper RJ and Schellens JH. Subcellular localization and distribution of the breast cancer resistance protein transporter in normal human tissues. Cancer research. 2001; 61:3458-3464.

7. Dai CL, Tiwari AK, Wu CP, Su XD, Wang SR, Liu DG, Ashby CR, Jr., Huang Y, Robey RW, Liang YJ, Chen LM, Shi CJ, Ambudkar SV, Chen ZS and Fu LW. Lapatinib (Tykerb, GW572016) reverses multidrug resistance in cancer cells by inhibiting the activity of ATP-binding cassette subfamily B member 1 and G member 2. Cancer research. 2008; 68:7905-7914.

8. Ma SL, Hu YP, Wang F, Huang ZC, Chen YF, Wang XK and $\mathrm{Fu} \mathrm{LW}$. Lapatinib antagonizes multidrug resistanceassociated protein 1-mediated multidrug resistance by inhibiting its transport function. Molecular medicine (Cambridge, Mass). 2014:390-399.

9. Tucker TG, Milne AM, Fournel-Gigleux S, Fenner KS and Coughtrie MW. Absolute immunoquantification of the expression of $\mathrm{ABC}$ transporters P-glycoprotein, breast cancer resistance protein and multidrug resistanceassociated protein 2 in human liver and duodenum. Biochemical pharmacology. 2012; 83:279-285.

10. van Waterschoot RA, Eman RM, Wagenaar E, van der Kruijssen CM, Rosing H, Beijnen JH and Schinkel AH. ABCC2, ABCC3, and ABCB1, but not CYP3A, Protect against Trabectedin-Mediated Hepatotoxicity. Clinical cancer research : an official journal of the American Association for Cancer Research. 2009; 15:7616-7623.

11. Wysowski DK and Swartz L. Adverse drug event surveillance and drug withdrawals in the United States, 1969-2002: the importance of reporting suspected reactions. Archives of internal medicine. 2005; 165:1363-1369.

12. Park BK, Kitteringham NR, Maggs JL, Pirmohamed M and Williams DP. The role of metabolic activation in druginduced hepatotoxicity. Annual review of pharmacology and toxicology. 2005; 45:177-202.

13. Luo M and Fu LW. Redundant kinase activation and resistance of EGFR-tyrosine kinase inhibitors. American journal of cancer research. 2014; 4:608-628.

14. Cetin B, Benekli M, Dane F, Boruban C, Gumus M, Oksuzoglu B, Kaplan MA, Tufan G, Sevinc A, Coskun U and Buyukberber S. Lapatinib plus Capecitabine for HER2Positive Advanced-Stage Breast Cancer in Elderly Women: Review of the Anatolian Society of Medical Oncology (ASMO) Experience. Breast care (Basel, Switzerland). 2013; 8:67-70.

15. Johnston S, Pippen J, Jr., Pivot X, Lichinitser M, Sadeghi S, Dieras V, Gomez HL, Romieu G, Manikhas A, Kennedy MJ, Press MF, Maltzman J, Florance A, O’Rourke L, Oliva C, Stein S, et al. Lapatinib combined with letrozole versus letrozole and placebo as first-line therapy for postmenopausal hormone receptor-positive metastatic breast cancer. Journal of clinical oncology : official journal of the American Society of Clinical Oncology. 2009; 27:5538-5546.

16. Wang H. Lapatinib for the treatment of breast cancer in the People's Republic of China. OncoTargets and therapy. 2014; 7:1367-1373.

17. B. Moy ER, L. Williams, T. Kelly, L. Nicolodi, J. D. Maltzman and P. E. Goss. Hepatobiliary abnormalities in patients with metastatic cancer treated with lapatinib. Journal of clinical oncology : official journal of the American Society of Clinical Oncology. 2009; 27(15s): 1043.

18. Loriot Y, Perlemuter G, Malka D, Penault-Llorca F, Boige V, Deutsch E, Massard C, Armand JP and Soria JC. Drug insight: gastrointestinal and hepatic adverse effects of molecular-targeted agents in cancer therapy. Nature clinical practice Oncology. 2008; 5:268-278.

19. Pal D and Mitra AK. MDR- and CYP3A4-mediated drugherbal interactions. Life sciences. 2006; 78:2131-2145.

20. Lin JH and Yamazaki M. Role of P-glycoprotein in pharmacokinetics: clinical implications. Clinical pharmacokinetics. 2003; 42:59-98.

21. Jagiello-Gruszfeld A, Tjulandin S, Dobrovolskaya N, Manikhas A, Pienkowski T, DeSilvio M, Ridderheim M and Abbey R. A single-arm phase II trial of first-line paclitaxel in combination with lapatinib in HER2-overexpressing metastatic breast cancer. Oncology. 2010; 79:129-135.

22. Di Leo A, Gomez HL, Aziz Z, Zvirbule Z, Bines J, Arbushites MC, Guerrera SF, Koehler M, Oliva C, Stein SH, Williams LS, Dering J, Finn RS and Press MF. Phase III, double-blind, randomized study comparing lapatinib plus paclitaxel with placebo plus paclitaxel as first-line treatment for metastatic breast cancer. Journal of clinical oncology : official journal of the American Society of Clinical Oncology. 2008; 26:5544-5552. 
23. Xu BH, Jiang ZF, Chua D, Shao ZM, Luo RC, Wang XJ, Liu DG, Yeo W, Yu SY, Newstat B, Preston A, Martin AM, Chi HD and Wang L. Lapatinib plus capecitabine in treating HER2-positive advanced breast cancer: efficacy, safety, and biomarker results from Chinese patients. Chinese journal of cancer. 2011; 30:327-335.

24. Ostapowicz G, Fontana RJ, Schiodt FV, Larson A, Davern TJ, Han SH, McCashland TM, Shakil AO, Hay JE, Hynan L, Crippin JS, Blei AT, Samuel G, Reisch J and Lee WM. Results of a prospective study of acute liver failure at 17 tertiary care centers in the United States. Annals of internal medicine. 2002; 137:947-954.

25. Temple R. Hy's law: predicting serious hepatotoxicity. Pharmacoepidemiology and drug safety. 2006; 15:241-243.

26. Leggas M, Panetta JC, Zhuang Y, Schuetz JD, Johnston B, Bai F, Sorrentino B, Zhou S, Houghton PJ and Stewart CF. Gefitinib modulates the function of multiple ATPbinding cassette transporters in vivo. Cancer research. 2006; 66:4802-4807.

27. Stewart CF, Leggas M, Schuetz JD, Panetta JC, Cheshire PJ, Peterson J, Daw N, Jenkins JJ, 3rd, Gilbertson R, Germain GS, Harwood FC and Houghton PJ. Gefitinib enhances the antitumor activity and oral bioavailability of irinotecan in mice. Cancer research. 2004; 64:7491-7499.

28. Midgley RS, Kerr DJ, Flaherty KT, Stevenson JP, Pratap SE, Koch KM, Smith DA, Versola M, Fleming RA, Ward C, O'Dwyer PJ and Middleton MR. A phase I and pharmacokinetic study of lapatinib in combination with infusional 5-fluorouracil, leucovorin and irinotecan. Annals of oncology : official journal of the European Society for Medical Oncology / ESMO. 2007; 18:2025-2029.

29. Geyer CE, Forster J, Lindquist D, Chan S, Romieu CG, Pienkowski T, Jagiello-Gruszfeld A, Crown J, Chan A, Kaufman B, Skarlos D, Campone M, Davidson N, Berger M, Oliva C, Rubin SD, et al. Lapatinib plus capecitabine for HER2-positive advanced breast cancer. The New England journal of medicine. 2006; 355:2733-2743.

30. Chu I, Blackwell K, Chen S and Slingerland J. The dual ErbB1/ErbB2 inhibitor, lapatinib (GW572016), cooperates with tamoxifen to inhibit both cell proliferation- and estrogen-dependent gene expression in antiestrogenresistant breast cancer. Cancer research. 2005; 65:18-25.

31. Moy B and Goss PE. Lapatinib: current status and future directions in breast cancer. The oncologist. 2006; 11:10471057.

32. Mir O, Berveiller P, Ropert S, Goffinet F, Pons G, Treluyer $\mathrm{JM}$ and Goldwasser F. Emerging therapeutic options for breast cancer chemotherapy during pregnancy. Annals of oncology : official journal of the European Society for Medical Oncology / ESMO. 2008; 19:607-620.

33. Borowski E, Bontemps-Gracz MM and Piwkowska A. Strategies for overcoming ABC-transporters-mediated multidrug resistance (MDR) of tumor cells. Acta biochimica Polonica. 2005; 52:609-627.
34. Leonard GD, Polgar $\mathrm{O}$ and Bates SE. ABC transporters and inhibitors: new targets, new agents. Current opinion in investigational drugs (London, England : 2000). 2002; 3:1652-1659.

35. Bence AK, Anderson EB, Halepota MA, Doukas MA, DeSimone PA, Davis GA, Smith DA, Koch KM, Stead AG, Mangum S, Bowen CJ, Spector NL, Hsieh S and Adams VR. Phase I pharmacokinetic studies evaluating single and multiple doses of oral GW572016, a dual EGFR-ErbB2 inhibitor, in healthy subjects. Investigational new drugs. 2005; 23:39-49.

36. Burris HA, 3rd, Hurwitz HI, Dees EC, Dowlati A, Blackwell KL, O’Neil B, Marcom PK, Ellis MJ, Overmoyer B, Jones SF, Harris JL, Smith DA, Koch KM, Stead A, Mangum $\mathrm{S}$ and Spector NL. Phase I safety, pharmacokinetics, and clinical activity study of lapatinib (GW572016), a reversible dual inhibitor of epidermal growth factor receptor tyrosine kinases, in heavily pretreated patients with metastatic carcinomas. Journal of clinical oncology : official journal of the American Society of Clinical Oncology. 2005; 23:53055313.

37. Patel N, Joseph C, Corcoran GB and Ray SD. Silymarin modulates doxorubicin-induced oxidative stress, Bcl-xL and p53 expression while preventing apoptotic and necrotic cell death in the liver. Toxicology and applied pharmacology. $2010 ; 245: 143-152$.

38. Karaduman D, Eren B and Keles ON. The protective effect of beta-1,3-D-glucan on taxol-induced hepatotoxicity: a histopathological and stereological study. Drug and chemical toxicology. 2010; 33:8-16.

39. Pieniazek A, Czepas J, Piasecka-Zelga J, Gwozdzinski K and Koceva-Chyla A. Oxidative stress induced in rat liver by anticancer drugs doxorubicin, paclitaxel and docetaxel. Advances in medical sciences. 2013; 58:104-111.

40. Chan JY, Chu AC and Fung KP. Inhibition of P-glycoprotein expression and reversal of drug resistance of human hepatoma HepG2 cells by multidrug resistance gene (mdr1) antisense RNA. Life sciences. 2000; 67:21172124.

41. Fu L, Liang Y, Deng L, Ding Y, Chen L, Ye Y, Yang X and Pan Q. Characterization of tetrandrine, a potent inhibitor of P-glycoprotein-mediated multidrug resistance. Cancer chemotherapy and pharmacology. 2004; 53:349-356.

42. Ford JM and Hait WN. Pharmacology of drugs that alter multidrug resistance in cancer. Pharmacological reviews. 1990; 42:155-199.

43. Chen LM, Liang YJ, Zhang X, Su XD, Dai CL, Wang FP, Yan YY, Tao LY and Fu LW. Reversal of P-gpmediated multidrug resistance by Bromotetrandrine in vivo is associated with enhanced accumulation of chemotherapeutical drug in tumor tissue. Anticancer research. 2009; 29:4597-4604.

44. Yamada $\mathrm{H}$ and Sano $\mathrm{Y}$. The biotinylation of the rabbit serotonin antibody and its application to immunohistochemical studies using the two-step ABC 
method. Histochemistry. 1985; 83:285-289.

45. Shi Z, Liang YJ, Chen ZS, Wang XW, Wang XH, Ding Y, Chen LM, Yang XP and Fu LW. Reversal of MDR1/Pglycoprotein-mediated multidrug resistance by vector-based RNA interference in vitro and in vivo. Cancer biology \& therapy. 2006; 5:39-47.

46. Livak KJ and Schmittgen TD. Analysis of relative gene expression data using real-time quantitative PCR and the 2(-Delta Delta C(T)) Method. Methods (San Diego, Calif). $2001 ; 25: 402-408$. 